\title{
Flicker observation light induces diameter response in retinal arterioles: a clinical methodological study
}

\author{
E Nagel, W Vilser
}

Br J Ophthalmol 2004;88:54-56

\begin{abstract}
Aim: To investigate diameter changes in retinal arterioles in response to flicker variations of the examination light.

Methods: One randomised eye of five healthy subjects (mean age 33.8 (SD 1.6) years) was examined. The arterial diameter response to flicker light $(12.5 \mathrm{~Hz}, 530-600 \mathrm{~nm}$, duration 20 seconds) was automatically and continuously measured online three times by retinal vessel analyser (RVA) and once offline from flash images using the VesselMap program.

Results: An arterial diameter response to flicker light was found both by RVA and by analysis of flash images $(p<0.001)$. The maximum induced dilation reached at the end of the flicker period was $+7.4 \%$ (SD $2.4 \%$ ) in the RVA measurements and $+3.5 \%(0.8 \%)$ in the photographs $(p=0.01)$. In both techniques the vascular diameter overshot the baseline approximately 10 seconds. In the RVA measurements a minimum of $-4.6 \%(1.9 \%)(p=0.01)$ was measured 22 (4.7) seconds after the end of flicker exposure. Conclusion: Flicker evoked response for retinal arterioles was found both by RVA and by analysis of flash images. The authors believe that the method is suitable for the quantitative investigation of retinal vasosclerosis, especially in association with arteriosclerotic and hypertensive systemic disease.
\end{abstract}

M odern imaging techniques have shown that enhanced neuronal activity leads to increased blood flow in corresponding areas of the brain. ${ }^{1-6}$ Clinical investigations have demonstrated increased blood flow rates of the light adapted eye compared to darkness in the optic nerve and choroid by laser Doppler velocimetry (LDV) ${ }^{78}$ and in the ophthalmic artery and central retinal artery by the duplex method. ${ }^{9}$ Orienting studies on the diameter of major retinal vessels using the retinal vessel analyser (RVA) have also shown blood flow to increase with brightness. ${ }^{10}$ An artificial form of light exposure is flicker light. The term denotes illumination alternating in brightness (luminance flicker) or colour (equiluminant chromatic flicker) at a frequency of approximately $1-50 \mathrm{~Hz} .{ }^{11}$ Animal experiments have shown an increase in laser Doppler blood flow in the optic nerve head in response to flicker light. ${ }^{12}{ }^{13}$ A number of studies have improved our understanding of the ocular neurovascular coupling of flicker induced blood flow changes in the optic papilla by LDV ${ }^{11-15}$ and have established correlations with functional parameters such as electroretinography. ${ }^{16}$ Analysis of retinal vessel diameters in fundus photographs demonstrated vessel dilation immediately after flicker provocation. ${ }^{17}$ Investigations with the RVA under green light with additional blue flicker light showed a change in the arterial vessel diameter of up to $+4.2 \% .{ }^{18}$ With its constant, relatively bright observation light and a superimposed flicker light, the technique used in the latter study does not produce an optimal luminance flicker. A flicker characterised by a stronger contrast can induce possibly a greater change in the calibre of retinal vessels and could be a preferred method for investigating vessel reactivity. The present study tested the following hypotheses:

- periodic changes of the observation light simulate luminance flicker to induce diameter changes in retinal arterioles;

- the changes are quantifiable by an online automated technique based on the RVA, ${ }^{19-21}$ as well as by offline analysis of digital images. ${ }^{22}$

\section{MATERIALS AND METHODS}

One eye of five healthy volunteers (mean age 33.8 (SD 1.6) years, refractive error $<$ l dioptre) was examined. At the start of the study the ophthalmological baseline status was determined and mydriasis was induced with tropicamide. The fundus was examined under green light. After a period of at least 1 minute, during which the eye was allowed to adapt to the retinal camera, online measurements with the RVA were commenced. After the baseline vessel diameter was measured for at least 60 seconds, provocation with flicker light of the same wavelength was performed for 20 seconds, and the response was observed for at least 60 seconds after the end of flicker exposure. The cycle was then repeated twice. Using the same position, filter, and focus setting on the retinal camera the flicker provocation of 20 seconds was repeated and the vessel response observed by flashed images. During the examination, the systemic blood pressure (BP) was monitored at 1 minute intervals.

The vessel diameter was measured with the RVA (Imedos Weimar, Germany). This consists of a retinal camera, a CCD measuring camera for electronic online image acquisition, and a PC for system control, analysis, and archiving of the results. ${ }^{19-21}$ An artificial vessel section of each eye measuring approximately $1.5 \mathrm{~mm}$ in length was evaluated. The vessel section was scanned in the measurement window at a frequency of 25 per second. The positions of the vessel edges were determined and the angle and diameter of the vessel were calculated automatically online. In the process, corrections were made for eye movements along the direction of measurement. The means of all segments of the vessel section in the measurement window were analysed. For statistical purposes, the means for 5 second time intervals were calculated.

The fundus images were taken with the RVA using the FF 450 retinal camera (Zeiss, Jena, Germany) and the VisualIS electronic image processing and archiving system (Imedos, Weimar, Germany). The vessel diameter was automatically determined on the digitised black and white images using the VesselMap program (Imedos, Weimar, Germany). Following correction for the image position, an analysis window was placed over the vessel segment, and the diameter was then 
measured fully automatically in a procedure similar to that used with the RVA. ${ }^{22}$ Again, the mean of the vessel segment was used and, for statistical analysis, the measurements of images of 5 seconds long time slices were combined. Flicker light was generated by means of rectangular interruption of the green observation light of the RVA (530-600 nm, illumination at the fundus approximately 6500 lux) at $12.5 \mathrm{~Hz}$ over the entire $30^{\circ}$ image field.

Variance analysis for repeated measurements and the Wilcoxon test were applied to the data for statistical evaluation.

The study was approved by the ethics committee of the Thuringia State Medical Board, and all the subjects gave their written informed consent to participate in the study.

\section{RESULTS}

A diameter response of retinal arteries caused by flicker light could be observed by both examinations methods (ANOVA, in each case $\mathrm{p}<0.001$, figs $\mathrm{l}$ and 2 ). The peak diameter response immediately after flicker provocation was $+7.4 \%$ (SD 2.4\%) in the RVA measurements and $+3.5 \%(0.8 \%)$ in the flash photograph analysis (in both cases $\mathrm{p}=0.01$ ). Dilation subsided immediately after flicker exposure, and the vessel diameter overshot the baseline about 10 seconds afterward, resulting in slight constriction. The RVA measurement showed a minimum diameter of $-4.6 \%$ (SD $1.9 \%$ ) $(p=0.01) 22(4.7)$ seconds after the end of flicker provocation. The systemic blood pressure did not change significantly during the examination.

\section{DISCUSSION}

The present study measured the change in the diameter of retinal arteries during and after stimulation by flicker modification of the observation light of the retinal camera and RVA. This involved minor manipulation of the illumination system, whereby the observation light is interrupted. This produces a luminance flicker in the green wavelength range at a frequency of $12.5 \mathrm{~Hz}$, which lies in the optimum luminance flicker range of $10-20 \mathrm{~Hz}$ determined by Riva et al. ${ }^{11}$ The diameter changes we observed with the RVA were greater than those observed in the study by Polak et al. ${ }^{18}$ One explanation for this could lie in the avoidance of continuous fundus illumination by the new stimulation method and the resulting greater flicker contrast. The temporal course of the arterial response essentially coincided with the RVA observations under mixed flicker light, ${ }^{18}$ although our 20 second provocation period was much shorter. We also found that the response subsided rapidly, after which the diameter overshot the baseline value to reach a minimum and then a return to

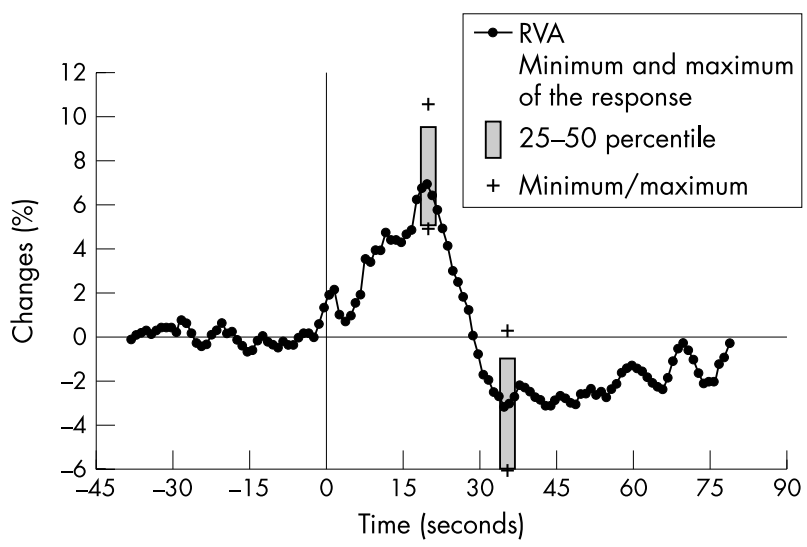

Figure 1 Mean arterial response to flicker light measured by RVA $(n=5)$.

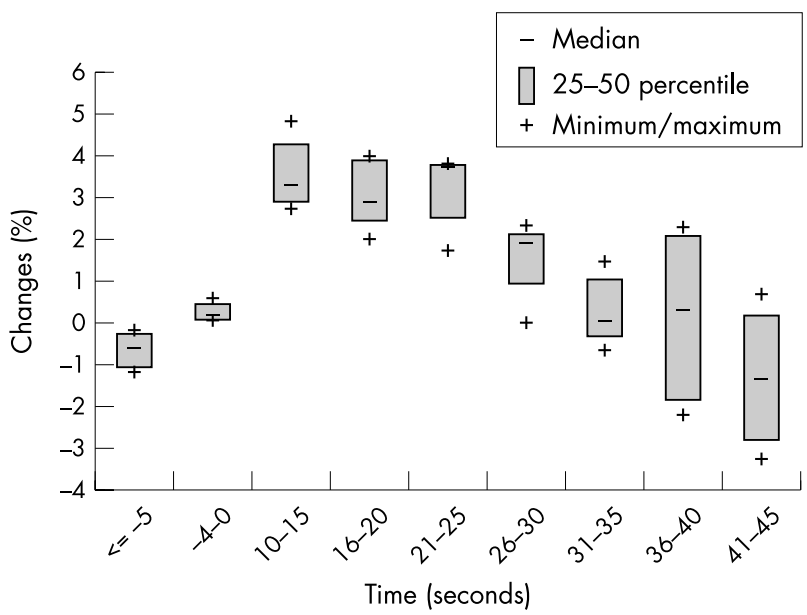

Figure 2 Mean arterial response to flicker light measured in flashed images $(n=5)$.

more or less the baseline value, reflecting regulative overcompensation.

Two different examination techniques, online analysis using a high sampling rate $(25 \mathrm{~Hz})$ and offline analysis of individual flash images, showed very similar temporal courses of the response but different peak values. The smaller dilation in the flash image series could be due to the greater light exposure produced by the photographic flash in comparison with the RVA observation light. On the images the flicker acts upon a higher baseline value and in relative terms represents a smaller additional stimulus. Another reason for the smaller response amplitudes in the individual images could be the coarser time resolution of the images, so that the peak response is not always recorded. The images were not taken corresponding to pulse in our study. The heart cycle influences the retinal vessel diameter ${ }^{23}$ and therefore the results could be influenced by the random photographic moment. However, the results coincide well with the values determined after flicker light provocation in fundus photography. ${ }^{17}$ In view of the lesser stress caused by the method, the greater relative diameter change it induces, and the simpler repetition of the provocation it affords with the possibility of averaging, the RVA technique therefore appears to be the more favourable of the two methods. Further clinical studies are needed now to systematically investigate the influence of age, systemic blood pressure, and antihypertensive therapy on the flicker response of retinal arterioles.

\section{Authors' affiliations}

E Nagel, Ophthalmic Private Practice, Anton-Sommer-Strasse 55, D-07407 Rudolstadt, Germany W Vilser, Technical University, PF 565100, D-98684 Ilmenau, Germany

Correspondence to: Mr E Nagel, MD, Anton-Sommer-Strasse 55, D-07407 Rudolstadt, Germany; e_a_nagel@t-online.de

Accepted for publication 2 April 2003

\section{REFERENCES}

1 Jueptner M, Weiller C. Review. Does measurement of regional cerebral blood flow reflect synaptic activity? Implications for PET and FMRI. Neuroimage 1995:2:148-56.

2 Beisteiner R, Gomiscek G, Erdler M, et al. [Correlation of results of localization by functional magnetic resonance tomography with magnetoencephalography.] [in German] Radiologe 1995;35:290-3.

3 Hajak G, Klingelhofer J, Schulz-Varszegi $M$, et al. Sleep apnea syndrome and cerebral hemodynamics. Chest 1996;110:670-9. 
4 Tamura M, Hoshi Y, Okada F. Localized near-infrared spectroscopy and functional optical imaging of brain activity. Philos Trans R Soc Lond B Biol Sci 1997;29:737-42.

5 Adler LJ, Gyulai FE, Diehl DJ, et al. Regional brain activity changes associated with fentanyl analgesia elucidated by positron emission tomography. Anesth Analg 1997:84:949.

6 Gsell W, De Sadeleer C, Marchalant Y, et al. The use of cerebral blood flow as an index of neuronal activity in functional neuroimaging: experimental and pathophysiological considerations. J Chem Neuroanat 2000;20:215-24.

7 Riva CE, Logean E, Petrig BL, et al. [Effect of dark adaptation on retinal blood flow.] [in German] Klin Monatsbl Augenheilkd 2000;216:309-10.

8 Longo A, Geiser M, Riva CE. [Effect of light on choroidal blood flow in the fovea centralis. ] [in German] Klin Monatsbl Augenheilkd 2000;216:31 1-2.

9 Havelius U, Hansen F, Hindfelt B, et al. Human ocular vasodynamic changes in light and darkness. Invest Ophthalmol Vis Sci 1999;40:1850-5.

10 Tobis M, Vilser W, Lang GE, et al. Influence of illumination on measurements of retinal vessel diameters. Invest Ophthalmol Vis Sci 1998;39(Suppl):995.

11 Riva CE, Falsini B, Logean E. Flicker-evoked response of human optic nerve head blood flow: Luminance versus chromatic modulation. Invest Ophthalmol Vis Sci 2001;42:756-62.

12 Riva CE, Harino S, Shonat RD, et al. Flicker evoked increase in optic nerve head blood flow in anaesthetised cats. Neurosci Lett 1991;128:291-6.

13 Riva CE, Cranstoun SD, Petrig BL. Effect of decreased ocular perfusion pressure on blood flow and flicker induced flow response in the cat optic nerve. Microvasc Res 1996;52:258-69.

14 Toi VV, Riva CE. Variations of blood flow at optic nerve head induced by sinusoidal flicker stimulation in cats. J Physiol 1995:482:189-202.
15 Riva CE, Mendel MJ, Petrig BL. Flicker induced optic nerve blood flow change. In: Kaiser HJ, Flammer J, Hendrickson P, eds. Ocular blood flow: Glaucoma meeting 1995. Basel: Karger, 1996:128-37.

16 Falsini B, Riva CE, Logean E. Flicker-evoked changes in human optic nerve blood flow: Relationship with retinal neural activity. Invest Ophthalmol Vis Sci 2002;43:2309-16.

17 Formaz F, Riva CE, Geiser M. Diffuse luminance flicker increases retinal vessel diameter in humans. Curr Eye Res 1997;16:1252-7.

18 Polak K, Schmetterer L, Riva CE. Influence of flicker frequency on flickerinduced changes of retinal vessel diameter. Invest Ophthalmol Vis Sci 2002;43:2721-6

19 Vilser W, Nagel E, Fuhrmann G, et al. Retinale Gefäßanalyse-Neue Möglichkeiten zur Untersuchungen von Netzhautgefäßen. In: Schmidt KG, Pillunat LE, eds. Fortbildung Glaukom Bd 3 Funktionsdiagnostik und pathogenetische Konzepte. Stuttgart-New York: Enke Verlag, 2000:73-91

20 Polak K, Dorner G, Kiss B, et al. Evaluation of the Zeiss retinal vessel analyser. Br J Ophthalmol 2000;84:1285-90.

21 Blum M, Bachmann K, Wintzer D, et al. Noninvasive measurement of the Bayliss effect in retinal autoregulation. Graefes Arch Clin Exp Ophthalmol 1999;237:296-300

22 Nagel E, Münch K, Vilser W. Durchmesserbestimmung von Netzhautgefäßabschnitten in digitalen Fundusfotografien. Eine experimentelle Studie zur Methodik und Reproduzierbarkeit. Klin Monatsbl Augenheilkd 2001;218:616-20

23 Chen HC, Patel V, Wiek J, et al. Vessel diameter changes during the cardiac cycle. Eye 1994:8:97-103.

\section{Video reports}

To view the video reports in full visit our website www.bjophthalmol.com and click on the link to video reports.

- Feeder vessel treatment with high speed ICG angiography. D Stanescu-Segall, G Coscas, F Coscas, G Soubrane

- Endoscopy to aid anterior segment surgery. J E Moore, A Sharma

- Penetrating ocular injury due to a fish hook: surgical removal. SDM Chen, D Chiu, C K Patel

- Retinal ganglion cell axon response to guidance molecules S F Oster, D W Sretavan

- Marin-Amat syndrome A Jogiya, C Sandy

- Excision of subcutaneous dirofilariasis of the eyelid D Mallick, T P Ittyerah

- Thixotropy: a novel explanation for the cause of lagophthalmos after peripheral facial nerve palsy. M Aramideh, J H T M Koelman, P P Devriese, F VanderWerf, J D Speelman

- Surgical revision of leaking filtering blebs with an autologous conjunctival graft. $K$ Taherian, A Azuara-Blanco

- Dipetalonema reconditum in the human eye. T Huynh, J Thean, R Maini

- Evaluation of leucocyte dynamics in mouse retinal circulation with scanning laser ophthalmoscopy. H Xu, A Manivannan, G Daniels, J Liversidge, P F Sharp, J V Forrester, I J Crane

- An intraocular steroid delivery system for cataract surgery. D F Chang

- Pearls for implanting the Staar toric IOL. D F Chang

- Capsule staining and mature cataracts: a comparison of indocyanine green and trypan blue dyes. D F Chang 